\title{
SOCIEDADE DA INFORMAÇÃO E LINGUAGEM: AS NOVAS TECNOLOGIAS E O CAMINHO PARA A CONSTRUÇÃO DE PALAVRAS E SENTIDOS
}

\section{THE SOCIETY OF INFORMATION AND LANGUAGE: NEW TECHNOLOGIES AND WAYS TO THE CONSTRUCTION OF WORDS AND MEANINGS}

\author{
Vinícius Oliveira Braz Deprá \\ Universidade de Santa Cruz do Sul \\ viniciusdepra@gmail.com
}

\begin{abstract}
RESUMO: A partir da sociedade pós-industrial, houve o delineamento de um novo paradigma social advindo da Sociedade da Informação, identificado especialmente pelas novas tecnologias e pelo impacto que a informação suscitou nos mais variados meios sociais. Nesse passo, quais seriam as relações existentes entre a Sociedade da Informação e o desenvolvimento da linguagem? Esse problema conduz a pesquisa, que buscará inicialmente contextualizar a sociedade da informação, para, em seguida, associá-la com os elementos da linguagem. Posteriormente, será analisado o relativismo linguístico e a ideia trabalhada por George Orwell em seu livro "1984". Em seguida, falase sobre a Sociedade da Informação, novas tecnologias e o advento de novas palavras e sentidos. Para tanto, utiliza-se o método de abordagem dedutivo. O método de procedimento será o monográfico. Quanto à técnica, utiliza-se a documentação indireta (pesquisa bibliográfica). Ao final, o estudo permitiu indicar que existe uma relação direta e indissociável entre a Sociedade da Informação e o desenvolvimento da linguagem, especialmente pelas integrações globais das novas tecnologias. Além disso, a adoção de novos símbolos linguísticos é necessária para acompanhar a velocidade da tecnologia e da informação, diante da expansão de novas palavras e novos sentidos. Com isso, constatou-se que a Sociedade da Informação se constitui em um vasto campo para o desenvolvimento, marcado pela mobilidade linguística e pelos novos horizontes de palavras e sentidos.
\end{abstract}

PALAVRAS-CHAVE: sociedade da informação; linguagem; novas tecnologias; construção de palavras e sentidos.

ABSTRACT: After the post-industrial society, there was the design of a new social paradigm arising from the Society of Information, especially identified by new technologies and the impact that the information raised in various social media. In this step, which would be the relationship between the information society and the development of language? This problem leads to research that will initially seek to contextualize the society of information, to then associate it with the language elements. After, the linguistic relativism will be analyzed, as the idea worked by George Orwell in his book "1984". Then, it talks about the Society of Information, new technologies and the advent of new words and meanings. For this, it uses the deductive method of approach. The method of procedure will be the monographic one. As for the technique, the indirect documentation (literature) will be used. Finally, the study concluded that there is a direct and inseparable link between the Information Society and the development of language, especially the 
global integration of new technologies. Moreover, the adoption of new linguistic symbols is necessary to monitor the speed of technology and information, given the expansion of new words and new meanings. In addition, it was found that the Information Society constitutes a vast field for the development, marked by the linguistic mobility and new horizons of words and meanings.

KEYWORDS: society of Information; language; new technologies; construction of words and meanings.

\section{Introdução}

Com o advento da Sociedade da Informação, houve o delineamento de um novo paradigma social, caracterizado especialmente pela inserção de novas tecnologias na sociedade pós-industrial. Esse impacto causou profundas mudanças nas mais diversas áreas, sobretudo sociais, políticas, econômicas, e também na maneira com que se expressa e se desenvolve a linguagem.

Nesse passo, a estrutura tecnológica e cultural da comunicação passou a integrar o conjunto de uma comunidade global, mas quais seriam as relações existentes entre a Sociedade da Informação e o desenvolvimento da linguagem?

Esse problema conduz a presente pesquisa, a qual tem por objetivo geral identificar as relações existentes entre a Sociedade da Informação e a influência da linguagem nesse contexto em relação à construção de palavras e sentidos.

Para o desenvolvimento do estudo, inicia-se por uma contextualização da Sociedade da Informação e, em seguida, a partir de aspectos gerais, faz-se uma relação entre esta e a linguagem. Depois disso, identifica-se o relativismo linguístico, bem como a maneira com que esse conceito foi trabalhado no livro "1984" de George Orwell. Tendo por pano de fundo essa ideia de linguagem e compreensão do mundo retratada no referido livro, analisa-se a maneira pela qual a Sociedade da Informação tem incorporado a criação de palavras e sentidos, bem como de que forma essa circunstância tem influenciado o desenvolvimento da linguagem, identificado especialmente em razão advento das novas tecnologias.

Quanto à metodologia utilizada, adota-se a abordagem dedutiva. Além disso, o estudo é construído a partir do método de procedimento monográfico. Quanto às técnicas de pesquisa empregadas, utiliza-se essencialmente a documentação indireta (pesquisa bibliográfica).

Registra-se, ainda, que a temática a ser desenvolvida se justifica pela relevância sempre presente da influência da Sociedade da Informação em variados níveis, sobretudo a partir do impacto das novas tecnologias sobre a linguagem.

\section{Sociedade da Informação}

A partir da sociedade pós-industrial, passa-se a vivenciar a Sociedade da Informação: as inovações tecnológicas são visíveis, e essas características inovadoras delinearam um novo paradigma social, fundamentado sobretudo na informação (PEZZELLA; CAMARGO, 2009, p. 82). Isso é caracterizado, notadamente, pela inserção 
das novas tecnologias da informação, constituindo uma das características mais marcantes da nossa sociedade, o que afeta diretamente a vida social, política e econômica (GONÇALVES, 2003, p. 7).

A propósito, afirma-se que atualmente a tecnologia, nas diversas áreas do conhecimento, é o grande móbil da sociedade (ADOLFO, 2008, p. 225). Tanto é assim que a Sociedade da Informação trouxe consigo a evidência tecnológica de novos meios de comunicação e, por meio deles, os modos e as maneiras de expressão foram exponencialmente multiplicados (ASCENSÃO, 2008, p. 1-2).

No mesmo sentido, ensina Manuel Castells (2005, p. 57), para quem as novas tecnologias da informação integram a humanidade em redes globais, na medida em que a comunicação a partir dos computadores gera uma gama imensurável de comunidades.

Aliás, essa revolução informacional pressupõe a substituição da produção da informação, havendo uma interpenetração mais complexa entre os diversos ramos sociais e de produção (LOJKINE, 2002, p. 238-239). Tudo isso porque houve uma adaptação dessa nova realidade, fundada no fluxo de informações, em virtude das mais variadas fontes de inovações tecnológicas (MAGLIAVACCA, 2012, p. 68)

De todo modo, essa nova interface e seus impactos sociais continuam a transformar a maneira pela qual nós imaginamos a informação, e essas mudanças compõem uma forma de arte genuína de eficiência (JOHNSON, 1997, p. 242).

A informação, portanto, passa a representar "fontes de produção de riquezas, sendo consideradas na atualidade 'bens econômicos primordiais'." (LÉVY, 1996, p. 3536). Tanto é assim que a informação se constitui no principal mecanismo de estruturação social, na medida em que os fluxos de mensagens entre as redes revelam 0 encadeamento básico da organização social (CASTELLS, 1999, p. 573).

Nesse contexto, a Sociedade da Informação acaba por redefinir, rearticular e reescalonar os elementos da estrutura tecnológica e cultural da comunicação. (TRIVINHO, 1998, p. 116). A propósito, essa redefinição permite observar que a cognição intelectual adota um conjunto de símbolos linguísticos próprios da coletividade, pois a natureza social acaba integrando o conjunto de uma comunidade global (LÉVI, 2003).

Ocorre que essa transformação a partir da informação parece indicar uma transformação também a partir da linguagem, da maneira como a experiência social desencadeia o conhecimento. Tanto é assim que Humberto Maturana chegou a afirmar que "Nós, seres humanos, existimos na linguagem" (2001, p. 154), ou seja, a nossa experiência como seres humanos decorre da linguagem e de coordenações e ações produzidas a partir dela (MATURANA, 2001, p. 154).

Ora, se existimos na linguagem, e a linguagem se transforma também pela evolução da informação, então a experiência social de igual modo ocorre na linguagem, consistindo em algo "tão concreto quanto qualquer operação no fluir das coordenações consensuais de ações nas quais surgimos e existimos." (MATURANA, 2001, p. 154)

Desse modo, passa-se a apresentar, no tópico seguinte, as principais relações indissociáveis entre a Sociedade da Informação e a Linguagem. 


\section{Sociedade da informação e linguagem}

Os ingredientes da linguagem são as palavras e as regras, que se estabelecem por meio de sinais (grafia) e sons (fonemas), cuja criação permite uma combinação a partir de senso de operações que irão para além dos arranjos atuais (PINKER, 1999, p. 269).

No campo da linguística, o acervo de palavras de um determinado idioma é mutável, pois enquanto algumas palavras deixam de ser utilizadas, outras são criadas como um fenômeno de renovação da própria língua. Nesse contexto, enquanto neologia está associada com o processo de criação lexical, o neologismo está associado com o produto dessa criação, com a palavra em si (ALVES, 1994, p. 1).

São diversas as espécies de neologismos. Dentre eles, destacam-se os neologismos semânticos, os quais são caracterizados pela ausência de uma mudança formal em palavras já existentes; a mudança que os distingue, ao contrário, diz respeito aos significados associados com a unidade léxica (ALVES, 1994, p. 63). Desse modo, não se está a analisar o campo da denotação ou conotação, mas sim o neologismo conceitual, que irá acrescentar significados aos próprios dicionários, identificando uma unidade léxica polissêmica.

Como se pode observar, a mudança é sempre ponto de referência dos neologismos, estando eles associados com a evolução da própria sociedade (CARVALHO, 1984, p. 8), significando dizer, portanto, que "a criação [de uma palavra ou de um sentido] é um ato social, uma tentativa de impor uma visão de mundo a uma comunidade" (CARVALHO, 1984, p. 10)

$\mathrm{O}$ avanço da tecnologia, aliado à velocidade dos acontecimentos em nosso mundo globalizado, tem consagrado uma constante mudança e evolução especialmente no que tange ao acesso às informações e à sua compreensão.

A Sociedade da Informação, conforme visto no capítulo anterior, tem embasado continuamente uma produção imaterial, no sentido de contribuir para o acesso à informação e enfatizando a necessidade de uma linguagem que caminhe na mesma velocidade. Essa linguagem se beneficia especialmente das relações existentes com a característica de não-rivalidade, viabilizadas pelas formas de produção da sociedade advindas da cooperação e desenvolvimento da informação (SIMON; VIEIRA, 2008, p. 26)

Com efeito, é através desse compartilhamento e cooperação que também se desenvolve o conhecimento na Sociedade da Informação, a partir de uma reciprocidade com arranjos frutíferos que irão perpetuar desde o aprendizado até o avanço e a inovação da tecnologia (PLONSKI, 2004, p. 98).

Aliás, "o homem é um animal tecnológico e a mudança tecnológica é o fator fundamental na evolução humana" (FERKISS, 1976, p. 24). E, com isso, evidencia-se uma relação direta entre linguagem e a evolução do conhecimento. Isso porque, é através das trocas com o outro, por meio da linguagem, que existe uma repercussão a partir da subjetividade enquanto forças de deslocamento, derivadas da estruturação cognitiva num espaço simbólico entre o interagir e o construir (AXT, 2000, p. 71).

Essa relação entre linguagem e conhecimento na Sociedade da Informação traz, originariamente, o estabelecimento de uma relação individual, significa dizer: cada indivíduo traz consigo uma carga valorativa em decorrência de suas próprias vivências, aquilo que Hans-Georg Gadamer denominou de "pré-conceitos". 
Os pré-conceitos têm por finalidade estabelecer juízos prévios para que se possa examinar os momentos da coisa em si (GADAMER, 2005, p. 360). Mais do que isso: os pré-conceitos correspondem à tradição e ao produto das relações sociais para a construção de um horizonte fundamentado em pressupostos prévios de sentido. Assim, o pensamento passa a ser entendido como produto do nosso horizonte interior, resultado da tradição em que estamos inseridos (PALMER, 2009, p. 186).

Nesse sentido, a situação presente da linguagem individual estabelece o conceito de horizonte, o qual diz respeito a todas as possibilidades que podem ser alcançadas desde determinado ponto: "Horizonte é o âmbito de visão que abarca e encerra tudo o que pode ser visto a partir de um determinado ponto" (GADAMER, 2005, p. 399). Esse horizonte, outrossim, também está relacionado com a compreensão histórica, no sentido de que ela é anterior ao horizonte consciente, de modo que a construção dos sentidos é desenvolvida antes da nossa própria compreensão (GADAMER, 2005, p. 400).

Ainda para Gadamer (2005, p. 503), a linguagem tem papel fundamental no alcance dos sentidos, na medida em que se constitui condição imprescindível para que a compreensão possa ser alcançada, pois, afinal, a linguagem é instituída no meio universal que possibilita realizar a compreensão.

Essa ideia de que a linguagem traz em si o meio para a compreensão abre uma nova indagação: em que medida a linguagem influencia o pensamento? Ou ainda, em que medida o pensamento influencia a linguagem?

No âmbito da filosofia da linguagem, essas questões são tratadas a partir de diversas perspectivas. Uma delas, o chamado "relativismo linguístico", sugere que o pensamento está limitado à maneira pela qual a linguagem se desenvolve, o que será estudado mais no próximo capítulo.

\section{Relativismo linguístico, linguagem e informação: o livro "1984” de George Orwell}

O relativismo linguístico, também como a Hipótese Sapir-Whorf, ou ainda Whorfianismo, é um conceito paradigma na linguística e também na ciência cognitiva, que sustenta que a estrutura de uma língua afeta a cognição ou visão de mundo de seus indivíduos. Com efeito, a partir dessa hipótese, criada na década de 1920 e 1930, os pensamentos e comportamentos são determinados (ou estão, pelo menos parcialmente influenciados) pela linguagem (ASH, 1999).

Para tanto, a maneira como as pessoas pensam seria fortemente afetada por suas línguas nativas, ou pela maneira pela qual cada pessoa dispõe de sua linguagem, ou seja: "Does the language we speak affect our perception of the world?"1 (GILBERT, 2006, p. 489)

Muito embora seja uma ideia científica contestada, há pesquisas que concluem que categorias linguísticas têm uma influência sobre a forma como os indivíduos conceituam o seu mundo, sobre a forma como pensamos (BROSS; PFALLER, 2012, p. 19), permitindo observar que as diferenças linguísticas podem induzir diferenças cognitivas nãolingüísticas (KAY; KEMPTON, 1984, p. 77).

1 Tradução livre: "A linguagem que falamos afeta nossa percepção do mundo?" 
Essa ideia de relativismo linguístico foi adotada por George Orwell em seu livro "1984", adotando a Hipótese de Sapir-Whorf para criar uma linguagem própria - a "Novilíngua" (ou Newspeek no original):

George Orwell explored the deterministic model of the Sapir-Whorf Hypothesis through the language of Newspeak in 1984. Although the language is in its infancy within the timeline of the novel, the intent behind Newspeak and its eventual results are clear $^{2}$ (FAIRCHILD, 2014, p. 6).

No referido livro, George Orwell narra a vida de Winston Smith, numa sociedade assistida (literalmente) pelo Big Brother, ou Grande Irmão. Ao trabalhar para o Ministério da Verdade, Winston contribui para que "O Partido" propague a verdade conforme sua própria convicção, inclusive destruindo tudo aquilo que não fosse adequado com a política.

A história entre as nações é recontada, as notícias são forjadas, com o intuito de conservar a simpatia pelo Partido e combater tudo aquilo que estiver em desconformidade com o sistema.

Os registros da história são sempre em apoio ao Partido, indicando que o passado não é necessário, pois com isso se controla o futuro e também o presente. Como uma resposta, erigiam-se três slogans no Ministério da Verdade: "on the White face of the Ministry of Truth came back at him: War is Peace, Freedom is Slavery, Ignorance is Strength"3 (ORWELL, 1990, p. 26)

Mas a dominação (ou ao menos sua ideia) foi além: em "1984" o controle da sociedade partia da linguagem, como forma de aprisionar o intelecto e reconstruir as pessoas sem que elas percebessem que as formas de pensamento estavam sendo direcionadas a determinado sentido de palavras, por meio das quais se expressaria o pensamento. Tanto é assim que havia uma "Polícia do Pensamento", mais temida que qualquer outra Patrulha: "It was the Police Patrol, snooping into people's Windows. The patrols did not matter, however. Only the Thought Police mattered"4 (ORWELL, 1990, p. 2).

Essa ideia se desenvolve a partir de uma linguagem própria, criada para aquele ambiente totalitário. Chamava-se: "Novilíngua". A finalidade, portanto, de uma nova língua foi designada para diminuir as fileiras do pensamento, seja atribuindo novos sentidos a palavras essenciais ou mesmo cortando palavras ao mínimo possível, ou seja, "was designed not to extend but to diminish the range of thought, and this purpose was indirectly assisted by cutting the choice of words down to a minimum"5 (ORWELL, 1990, p. 299).

Aliás, há um diálogo entre Winston e Syme, a quem coube escrever o dicionário da

2 Tradução livre: "George Orwell explorou o modelo determinístico da Hipótese de Sapir-Whorf através da linguagem do Newspeak em 1984. Embora a linguagem esteja engatinhando na linha do tempo do romance, a intenção por trás do Newspeak e seus resultados finais são claros."

3 Tradução livre: "Na face Branca do Ministério da Verdade voltou para ele: Guerra é Paz, Liberdade é Escravidão, Ignorância é Força."

4 Tradução livre: "Foi a patrulha da polícia, bisbilhotando as janelas das pessoas. As patrulhas não importavam, no entanto. Apenas a Polícia do Pensamento importava"

5 Tradução livre: "Foi projetado para não estender, mas para diminuir a gama de pensamento, e este objetivo foi indiretamente auxiliado por reduzir a escolha de palavras ao mínimo". 
Novilíngua, que expressa a conclusão e a necessidade de destruir palavras para que seja possível limitar o pensamento e a capacidade de criticar:

How is the Dictionary getting on?' said Winston, raising his voice to overcome the noise.

'Slowly,' said Syme. 'I'm on the adjectives. It's fascinating.'

$[\ldots]$

'The Eleventh Edition is the definitive edition,' he said. 'We're getting the language into its final shape -- the shape it's going to have when nobody speaks anything else. When we've finished with it, people like you will have to learn it all over again. You think, I dare say, that our chief job is inventing new words. But not a bit of it! We're destroying words -- scores of them, hundreds of them, every day. We're cutting the language down to the bone. The Eleventh Edition won't contain a single word that will become obsolete before the year $2050^{6}$ (ORWELL, 1990, p. 50-51, grifos do autor).

Partia-se do pressuposto, portanto, que se um pensamento ou se uma ideia não fosse passível de ser expressa em palavras, então esse pensamento ou essa mesma ideia não poderia existir na consciência do indivíduo.

Aliás, casos curiosos são encontrados no "Appendix" da obra em comento, especialmente no "The B Vocabulary", que consistia em palavras que haviam sido "deliberately constructed for political purposes: words, that is to say, which not only had in every case a political implication, but were intended to impose a desirable mental attitude upon the person using them"7 (ORWELL, 1990, p. 303).

Nesse contexto, o plano de Orwell para Novilíngua foi usar a linguagem para controlar os pensamentos, percepções e comunicação dos membros do Partido, operando como uma expressão literal do determinismo linguístico. A relação determinista entre linguagem e percepção é essencial para a teoria da Novilíngua, pois, em última análise, como referido anteriormente, se uma pessoa não associa uma palavra para representar um conceito, se este conceito é um objeto físico ou sentimento abstrato, então o conceito simplesmente não existe para essa pessoa:

Orwell's plan for Newspeak was to use the language to control the thoughts, perceptions, and communication of Party members in the fictional dystopia of Oceania. Newspeak operates as a literal expression of linguistic determinism. As a specific form of the Sapir-Whorf Hypothesis, linguistic determinism dictates: "the language people speak helps determine the very way they think about their physical and social world." It is the stronger of the two Sapir-Whorf doctrines, the

6 Tradução livre: "Como está o dicionário? disse Winston, levantando a voz para superar o barulho. "Lentamente", disse Syme. 'Eu estou nos adjetivos. É fascinante.' [...] "A décima primeira edição é a edição definitiva", disse ele. 'Estamos colocando a linguagem em sua forma final - a forma que terá quando ninguém falar mais nada. Quando terminarmos, pessoas como você terão que aprender tudo de novo. Você pensa, ouso dizer, que nosso principal trabalho é inventar novas palavras. Mas nem um pouco disso! Estamos destruindo palavras - dezenas delas, centenas delas, todos os dias. Estamos cortando a linguagem até o osso. A décima primeira edição não conterá uma única palavra que se torne obsoleta antes do ano 2050".

7 Tradução livre: "Deliberadamente construídos para fins políticos: palavras, isto é, que não só tiveram em todos os casos uma implicação política, mas tinham a intenção de impor uma atitude mental desejável à pessoa que as utiliza". 
second being linguistic relativity. The deterministic relationship between language and perception is essential to the theory of Newspeak. In the most extreme sense, if a person has no word to represent a concept, whether that concept is a physical object or abstract feeling, then the concept simply does not exist for that person ${ }^{8}$ (FAIRCHILD, 2014, p. 6).

Com isso, a ideia de diminuir as palavras não objetivava apenas alterar o léxico, mas continha sobretudo uma implicação social e política - a de impor uma atitude desejável sobre as pessoas.

Tendo por pano de fundo essa ideia retratada no livro "1984", bem como a teoria do relativismo linguístico, observa-se que a Sociedade da Informação tem uma relação essencial com o desenvolvimento da linguagem, na medida em que existe uma produção exponencial de novas palavras e novos sentidos, causada notadamente pelo avanço tecnológico. Essas circunstâncias serão tratadas no capítulo a seguir.

\section{Sociedade da informação, novas tecnologias e a criação de palavras e sentidos}

Conforme ensina Eugênio Rondini Trivinho, a tecnologia da informática tem representado cada vez mais a "instauração paulatina e irreversível de um mundo inteiramente outro, com características distintas daquele culturalmente irradiado sob o eixo dos media tradicionais." (TRIVINHO, 1998, p. 112)

Para o referido autor, as linguagens desencadeadas sobretudo pelo uso do computador representam uma nova compreensão quanto ao acesso ao sentido do trabalho, num complexo cada vez mais renovado pela tecnologia (TRIVINHO, 1998, p. 112). Essa situação já exige inclusive uma nova linguagem para que seja possível acompanhar o alcance das informações em seus mais variados níveis (JOHNSON, 1997, p. 18).

Isso vai ao encontro, inclusive, da ideia de Pierre Lévy e Michel Authier, para quem o conhecimento está no outro, pois "cada um traz ao saber sua parcela incomparável" (1995, p. 102), sendo necessário não apenas identificar o outro, mas também compreendê-lo, o que se aproxima da ideia de fusão de horizontes já trabalhada por Gadamer.

Nesse contexto, a criação de palavras e sentidos surge justamente como forma de acompanhar a Sociedade da Informação, uma simbiose que permite a adoção de neologismos próprios não apenas do ambiente tecnológico como também cultural, pois, de acordo com Lévy (1993), o mundo das comunicações e sobretudo o mundo da informática tem implicado frequentemente uma nova maneira de pensar e de conviver.

8 Tradução livre: "O plano de Orwell para a Novilíngua era usar a linguagem para controlar os pensamentos, percepções e comunicação dos membros do Partido na distopia fictícia da Oceania. Novilíngua opera como uma expressão literal do determinismo linguístico. Como uma forma específica da Hipótese de Sapir-Whorf, o determinismo linguístico dita: "a linguagem que as pessoas falam ajuda a determinar a maneira como pensam sobre seu mundo físico e social" É a mais forte das duas doutrinas Sapir-Whorf, a segunda sendo relatividade linguística. A relação determinística entre linguagem e percepção é essencial para a teoria do Newspeak. No sentido mais extremo, se uma pessoa não tem palavra para representar um conceito, se esse conceito é um objeto físico ou um sentimento abstrato, então o conceito simplesmente não existe para essa pessoa". 
A propósito, Thomas Kuhn já mencionava que o significado de uma palavra implica na maneira pelo qual seu uso "é empregado por meio da comunicação, levando-se em conta os membros da comunidade linguística em que essa mesma palavra não é corrente" (KUHN, 2006, p. 82). Desse modo, a linguagem existe a partir da comunidade e de seu sentido posto como forma de possibilitar a comunicação (AXT, 2000, p. 123).

Nesse contexto, é facilmente possível identificar a influência das novas tecnologias e sua relação com a linguagem.

No que diz respeito à internet, essa associação pode ser identificada de maneira ostensiva quando estamos "conectados" ou "navegando". Veja-se que o próprio sentido dessas palavras, decorrentes dos verbos conectar e navegar, é usual para o atual momento da tecnologia, e seria incompreendido se empregado no início do século passado, ou seria compreendido com outro sentido.

Isso remete à perspectiva do neologismo semântico, a partir do quê se pode identificar outros exemplos: A palavra "Navegador" hoje está associada com a ideia de software que permite a utilização da internet; a palavra "Rede" se relaciona ao ambiente virtual; o verbo "Surfar" também está associado à utilização da internet. Quanto ao neologismo lexical, houve a criação de palavras que trouxeram consigo novos sentidos, como por exemplo: os verbos "deletar", "googlear", "twittar". No âmbito do neologismo sintático, o prefixo "cyber" é amplamente utilizado: cyberdireito, cybercrimes, cyberataques, cyberbullying, cybercafé, etc.

Esses são apenas alguns exemplos presentes em nosso dia a dia, e que facilmente são compreendidos com as funções e sentidos que possuem.

Em dissertação específica sobre esse tema, que teve por finalidade analisar os neologismos na área da informática, especialmente os estrangeirismos, Sandra Delneri Petean Torrano concluiu que a área da informação é influenciada profundamente pela cultura externa, principalmente pela língua inglesa. Os neologismos, segundo a pesquisadora, são utilizados inclusive sem qualquer destaque em itálico, negrito ou aspas, como se já pertencessem ao léxico português, de modo que esses mesmos neologismos são habitualmente empregados como se já fossem do universo do próprio falante (TORRANO, 2010, p. 108).

Na mesma linha de pesquisa, recente tese também defendida na Universidade de São Paulo revelou que os neologismos provêm das mais variadas áreas do conhecimento, muito embora tenham na informática sua origem principal. De todo modo, o viés tecnológico contribui sobremaneira para a construção de palavras e sentidos, disseminando uma maneira mais profícua para a informação no meio social, destacando a importância da língua para o desenvolvimento, na medida em que ela é o elo para o próprio conhecimento (SIQUEIRA, 2015, p. 145).

Aliás, o advento de novas palavras e sentidos observados no contexto da Sociedade da Informação demonstra que "o homem tecnológico", ao assumir o papel de liderança no desenvolvimento de novas tecnologias, também se prepara para assumir o papel na evolução comunicacional (FERKISS, 1976, p. 167).

Com efeito, "words and rules give rise to the vast expressive power of language, allowing us to share the fruits of the vast creative power of thought"9 (PINKER, 1999, p.

9 Tradução livre: "palavras e regras dão origem ao vasto poder expressivo da linguagem, permitindo-nos compartilhar os frutos do vasto poder criativo do pensamento". 
287), de modo que o poder criativo do pensamento acaba sendo fortalecido pela evolução da própria linguagem.

Ora, com o advento das novas tecnologias, a Sociedade da Informação exige um sistema dinâmico, que permita a expansão da linguagem enquanto unidades de designação e criação de sentidos (BASILIO, 2011, p. 10).

Com isso, a linguagem dá "condições ao pensamento criador de enriquecer a língua, com economia formal na elaboração de novos conceitos" (CARVALHO, 2006, p. 197). No entanto, Luiz Gonzaga Silva Adolfo nos alerta que, ao mesmo tempo que a linguagem evolui a partir das novas tecnologias, talvez essa evolução advenha de aspecto decorrente da globalização, em obediência a uma matriz específica de desenvolvimento econômico e da ideologia própria de um país dominante (ADOLFO, 2001, p. 82).

O desenvolvimento de novos conhecimentos, tanto no contexto tecnológico quanto no social, tem indicado uma elevada mobilidade léxica, e as novas tecnologias de comunicação acabam provocando, de igual modo, profundas repercussões na formação de palavras e sentidos (ADAMO, 2010, p. 51).

Assim, a compreensão quanto aos efeitos simbólicos da linguagem leva em conta o fato de que o desenvolvimento dessa mesma linguagem é o primeiro mecanismo por meio do qual são ilimitadas as capacidades geradoras (BOURDIEU, 1996, p. 28).

Aliás, a criatividade lexical passa a revelar inclusive a vitalidade de uma língua, na medida em que a riqueza da comunicação é responsável inclusive por contribuir para o desenvolvimento científico, diante da nova inserção de sentidos (ALVES, 2001, p. 68).

Portanto, a Sociedade da Informação propicia um vasto campo para o desenvolvimento, o que decorre notadamente da dimensão exponencial de novas tecnologias. Nesse contexto, a linguagem tende a acompanhar cada vez mais essa evolução humana, contribuindo para o seu desenvolvimento e representando sobretudo um horizonte cada vez mais amplo de novas palavras e novos sentidos.

\section{Considerações finais}

O estudo permitiu indicar que existe uma relação direta e indissociável entre a Sociedade da Informação e o desenvolvimento da linguagem. Isso porque - as inovações tecnológicas, integradas em redes globais, fazem parte da estrutura social e invocaram a necessidade de serem adotados novos símbolos linguísticos capazes de acompanhar a construção de novas palavras e sentidos.

Além disso, a maneira como a linguagem acompanha o desenvolvimento humano foi apresentada a partir da moldura literária da obra "1984" de George Orwell, em que as palavras eram limitadas para que se pudesse limitar a capacidade de pensar.

A Sociedade da Informação, por outro lado, tem demonstrado uma construção exponencial de novas palavras e novos sentidos, fruto da velocidade da tecnologia, o que acaba afetando invariavelmente o pensamento e a capacidade de comunicação, em níveis cada vez mais sofisticados.

Essa construção é observada no dia a dia, facilmente identificada pelo uso da internet. Aliás, observou-se a existência de diversos tipos de neologismos, destacando-se 
o neologismo semântico, o lexical e também o sintático.

Verificou-se, ainda, que as novas tecnologias exigem, por si, um sistema linguístico dinâmico, na medida em que a riqueza da comunicação é indissociável do desenvolvimento da própria informação, demonstrando inclusive a vitalidade de uma língua.

Ao final, constatou-se que a Sociedade da Informação propicia um vasto campo para o desenvolvimento, delineado sobretudo pela mobilidade linguística, consistindo em um amplo horizonte para o desenvolvimento de novas tecnologias, novas palavras e novos sentidos.

\section{Referências}

ADAMO, G. La Neologia Italiana: panorama histórico, procesos de formación y nuevas tendencias en los neologismos de la prensa. In: ALVES, I. M. (Org). Neologia e neologismo em diferentes perspectivas. São Paulo: Paulistana, 2010. p. 35-61.

ADOLFO, L. G. S. Globalização e Estado Contemporâneo. São Paulo: Memória Jurídica, 2001.

ADOLFO, L. G. S. Obras privadas, benefícios coletivos: a dimensão pública do direito autoral na sociedade da informação. Porto Alegre: Sérgio Antônio Fabris Ed., 2008.

ALVES, I. M. Neologia e tecnoletos. In: ISQUERDO, A. N.; OLIVEIRA, A. M. P. P. de. (Org.) As ciências do léxico: lexicologia, lexicografia, terminologia. 2.ed. Campo Grande: UFMS, 2001. p. 23-29.

ALVES, I. M. Neologismo: Criação lexical. 2. ed. São Paulo: Ática, 1994.

ASCENSÃO, J. de O. Direito da Sociedade da Informação. Vol. VII. Coimbra: Coimbra Editora, 2008.

ASH, R. The Sapir-Whorf Hypothesis. 1999. Disponível em: <http://www.angelfire.com/journal/worldtour99/sapirwhorf.html>. Acesso em: 26 jun. 2016.

AXT, M. Linguagem e telemática: tecnologias para inventar-construir conhecimento. In: PELLANDA, N. M. C.; PELLANDA, E. C. (Org). Ciberespaço: um hipertexto com Pierre Lévy. Porto Alegre: Artes e Ofícios, 2000. p. 68-79.

BASILIO, M. Formação e classes de palavras no português do Brasil. 3. ed. São Paulo: Contexto, 2011.

BOURDIEU, P. A economia das trocas linguísticas: o que falar quer dizer. São Paulo: Edusp, 1996.

BROSS, F.; PFALLER, P. The decreasing Whorf-effect: A study in the classifier systems of 
Mandarin and Thai. Journal of Unsolved Questions. Mainz: Johannes Gutenberg University, v. 2, n. 2, p. 19-24, jul. 2012. Disponível em: < http://www.junq.info/wpcontent/uploads/downloads/2012/06/Whorf-effects.pdf>. Acesso em: 10 out. 2018.

CARVALHO, N. M. A Criação Neológica. In: CRUZ, A. D.; SEIDE, M. S. (Org). Revista Trama, v. 2, n. 4, p. 191-123, $2^{\circ}$ semestre de 2006. Cândido Rondon: UNIOESTE, 2006. Disponível em: <http://e-revista.unioeste.br/index.php/trama/article/download/681/574>. Acesso em: 10 out. 2018.

CASTELLS, M. A era da informação: economia, sociedade e cultura. v. 01: Sociedade em rede. 8. ed. Rio de Janeiro: Paz e Terra, 2005.

CASTELLS, M. A sociedade em rede. São Paulo: Paz e Terra, 1999.

CARVALHO, N. O que é neologismo. São Paulo: Brasiliense, 1984.

FAIRCHILD, K. Dystopian Language and Thought: The Sapir-Whorf Hypothesis Applied to Created Forms of English. Student research Paper 7. Greencastle: DePauw University, 2014. Disponível em: <http://scholarship.depauw.edu/cgi/viewcontent.cgi? article $=1008 \&$ context=studentresearch $>$. Acesso em: 15 jun. 2016.

FERKISS, V. C. O homem tecnológico: mito e realidade. 2. ed. Rio de Janeiro: J. Zahar, 1976.

GADAMER, H.-G.. Verdade e método I: traços fundamentais de uma hermenêutica filosófica. $7^{\mathrm{a}}$ ed. Petrópolis: Vozes, 2005.

GILBERT, A. et all. Whorf hypothesis is supported in the right visual field but not the left, Bethesda: US National Library of Medicine, v. 103, n. 2, p. 489-494, 2006. Disponível em: <http://www.pnas.org/content/103/2/489.full.pdf>. Acesso em: 10 out. 2018.

GONÇALVES, M. E. Direito da Informação - novos direitos e formas de regulação na sociedade da informação. Coimbra: Almedina, 2003.

JOHNSON, S. Interface Culture: how new technology transforms the way we create and communicate. San Francisco: Basic, 1997.

KAY, P.; KEMPTON, W. What Is the Sapir-Whorf Hypothesis? Arlington: American Anthropological Association, 1984. Disponível em: $<$ http://www1.icsi.berkeley.edu/ kay/Kay\&Kempton.1984.pdf>. Acesso em: 10 out. de 2018.

KUHN, T. O caminho desde A Estrutura: ensaios filosóficos, 1970-1993. São Paulo: UNESP, 2006.

LÉVY, P. A inteligência coletiva: por uma antropologia do ciberespaço. $5^{a}$ Ed. São Paulo: Loyola, 2003. 
LÉVY, P. As tecnologias da inteligência: o futuro do pensamento na era da informática. Rio de Janeiro: Editora 34, 1993.

LÉVY, P. O que é o virtual? São Paulo: Editora 34, 1996.

LÉVY, P.; AUTHIER, Michel. As árvores de conhecimentos. São Paulo: Escuta, 1995.

LOJKINE, J. A revolução Informacional. 3a . Edição. São Paulo: Cortez Editora, 2002.

MAGLIAVACCA, L. de A. A virtualização do processo como meio de concretização do direito fundamental à razoável duração do processo na sociedade da informação. In: ADOLFO, L. G. S. (Org.). Direitos Fundamentais na Sociedade da Informação. Florianópolis: UFSC/GEDAI, 2012. p. 67-89.

MATURANA, H. Cognição, ciência e vida cotidiana. Belo Horizonte: UFMG, 2001.

ORWELL, G. 1984. New York: Penguin Press, 1990.

PALMER, R. Hermenêutica. Lisboa: Edições 70, 2009.

PEZZELLA, M. C. C.; CAMARGO, R. A. L. Sociedade da Informação e as Redes Sociais. Rio Grande: JURIS - Revista da Faculdade de Direito, 2009. Disponível em: <https://www.seer.furg.br/juris/article/view/3208/1867>. Acesso em: 10 out. 2018.

PINKER, S. Words and rules: the ingredientes of language. New York: Harper Collins, 1999.

PLONSKI, G. A. Questões tecnológicas na sociedade do (des)conhecimento. In: SANTOS, L. W. dos [et al] (Org). Ciência, tecnologia e sociedade: o desafio da interação. Londrina: IAPAR, 2004. p. 83-99.

SIMON, I.; VIEIRA, M. S.; PRETTO, N. De L. (Org.) Além das redes de colaboração: internet, diversidade cultural e tecnologias do poder. Salvador: EDUFBA, 2008.

SIQUEIRA, J. C. Neologismos na Ciência da Informação. 2015. 179 f. Tese (Doutorado). Programa de Pós-Graduação em Filologia e Língua Portuguesa, Universidade de São Paulo: São Paulo, 2015.

TORRANO, S. D. P. Produtividade e Criatividade do Léxico: os neologismos na área da informática. Dissertação. 2010. 123 f. (Dissertação). Programa de Pós-Graduação em Filologia e Língua Portuguesa, Universidade de São Paulo: São Paulo, 2010.

TRIVINHO, E. Redes: Obliterações no fim do século. São Paulo: Annablume, 1998. 